\title{
Acute toxicity tests and dyeing potentials of three azo dyes from Pyocyanin, produced by Pseudomonas aeruginosa from farmlands
}

\author{
A. C. Nwosu ${ }^{1 *}$ and I. O. Okerulu ${ }^{1}$ \\ ${ }^{1}$ Pure and Industrial Chemistry Department, Faculty of Physical Sciences, Nnamdi Azikiwe University, \\ Awka, Anambra State. \\ *Corresponding Author's emailnwosuadaora101 @ gmail.com, +234 8039326062 \\ Received 04 February 2021; accepted 30 March 2021, published online 8 April 2021
}

\begin{abstract}
The admiration for colours by man has made dyes to have very useful applications on a great variety of materials. Pyocyanin (PCN) or 5-methyl-1-hydroxyphenazine, a phenazine derivative biosynthesized by Pseudomonas aeruginosa isolated from the stressed soil of a farmland at Awka was used to prepare three azo dyes namely, pyocyanin azophenol, pyocyanin azo-1-naphthol and pyocyanin azo-2-naphthol. The PCN was treated with $\mathrm{SOCl}_{2}$ to convert it to the chloro analogue. Treatment of chloro analogue with $\mathrm{NaCN}$ in ethanol and subsequent acid hydrolysis gave the carboxylic acid from which the amide was obtained after treatment with $\left(\mathrm{NH}_{4}\right)_{2} \mathrm{CO}_{3}$ and heat. The amide was converted to the amine by Hoffman's amide degradation. The amine was diazotized and coupled with phenol, 1-naphthol and 2-naphthol to give the three azo dyes respectively. UV-VIS and infrared spectra of the compounds agreed with the assigned structures. Acute Toxicity $\left(\mathrm{LD}_{50}\right)$ tests showed the compounds to be reasonably non-toxic. Dyeing potentials of the Pyocyanin (PCN), PCN azophenol, PCN azo-1-naphthol and PCN azo-2-naphthol by mordant dyeing on cotton, silk and nylon textile materials showed them to have blue, dark green, purplish-brown and red colours respectively. The dyes were reasonably fast to light, washing, rubbing, alkali and acid. Pyocyanin, Pyocyanin azophenol, Pyocyanin azo-1-naphthol and pyocyanin azo-2naphthol produced from Pseudomonas aeruginosa isolated from farmland soil can be used effectively to dye cotton, silk and nylon textile materials.
\end{abstract}

Keywords; Pyocyanin (PCN), azo dyes, Pseudomonas aeruginosa

\section{Introduction}

Pyocyanin is a blue redox-active secondary metabolite and is responsible for the blue-green characteristic colour of the Pseudomonas species. Pyocyanin displays broad-spectrum bactericidal effects and is believed to protect the producing organisms against competing microbes [1]. Pyocyanin is extracted from active broth cultures of the bacteria Pseudomonas aeruginosa which can be isolated from soil, marine bodies and clinical specimen such as urine, surgical wound infections, sputum from patients with cystic fibrosis infected with P. aeruginosa, etc [2].

Research has also revealed that Pyocyanin, like most phenazines are economically important to man as they have been found to have potential use as drugs, due to their antimicrobial properties; food colourants and fabric dyes, due to their rich pigmentation [1][3]. In the past, painters had used natural dyes extracted from plants, insects, mollusks and minerals for their paintings. Some synthetic dyes usually show different levels of toxicity and may serve as a source of chemical hazards in our environment [4]. The production of some dyes has also rapidly declined due to the toxic nature and carcinogenic effects of the chemicals used in preparing them. Since Nature has and will always dominate and take priority over synthetic and artificial substances, natural dyeing is gradually making its way in the global market and the production of naturally dyed ecofriendly textiles itself is a good way to save the environment from hazardous synthetic dyes [5]. In order to further research on other sources of natural dyes with potentially lesser chemical/environmental hazards, this study was aimed at synthesizing dyes from Pyocyanin as well as determining their toxicity and dyeing potentials on cotton, silk and nylon materials.

\section{Materials and Methods \\ Sample collection and preparation:}

Soil samples from farmlands within Awka were collected in sterile containers. The bacteria Pseudomonas aeruginosa, was cultivated and isolated by measuring $1 \mathrm{~g}$ each of the soil samples 
into 14 sterilized petri dishes and mixed with 20 $\mathrm{mL}$ each of the prepared and decontaminated centrimide agar laced with glycerol. The mixture was then left to settle and solidify [6]. The dishes were incubated at $37^{\circ} \mathrm{C}$ for 24 hours. The isolated bacteria, Pseudomonas aeruginosa, were then identified using colony, culture and morphology, gram-staining and biochemical tests. Nutrient/centrimide broth was prepared and autoclaved and then used to ferment and grow the bacteria for 96 hours in an incubator shaker [6]. Pyocyanin was produced naturally in the process and was extracted using chloroform solvent in a 1:1 ratio with the fermentation broth. The pyocyanin was then characterized by acidifying it with $0.2 \mathrm{M}$ of $\mathrm{HCl}$, which resulted in a colour change from blue to red and then it absorbed at a wavelength of $520 \mathrm{~nm}$ in the UV-VIS spectrum using the spectrophotometer.

\section{Synthesis of phenazine azo compounds:}

Pyocyanin (PCN $10 \mathrm{~g}$ ) was reduced to its colourless form by treating it with a solution of sodium dithionite $(8 \mathrm{~g})$ and Sodium bicarbonate ( 8 g) dissolved in $250 \mathrm{~mL}$ of water. PCN was then converted to the chloro analogue by treating it with Thionyl chloride $(20 \mathrm{~mL})$. The chloro analogue $(9.3 \mathrm{~g})$ was then treated with sodium cyanide $(0.5 \mathrm{~g})$ in ethanol $(50 \mathrm{~mL})$ and subsequently hydrolysed to give the carboxylic acid from which the amide was obtained after treatment with ammonium carbonate $(2 \mathrm{~g})$ and heat. The amide was converted to an amine by Hoffman's amide degradation; this was done by dissolving Sodium hydroxide (12.5 g) in distilled water $(65 \mathrm{~mL})$ in a $100 \mathrm{~mL}$ beaker. It was stirred and chilled to $5{ }^{\circ} \mathrm{C}$ in an ice-bath. Bromine (3.2 $\mathrm{mL}$ ) was slowly added to the $\mathrm{NaOH}$ solution with a dropper and stirred while keeping the solution at $0-5{ }^{\circ} \mathrm{C}$. The amide compound $(9.3 \mathrm{~g})$ was then added to the sodium hypobromite solution (80 $\mathrm{mL}$ ) formed in small portions and stirred during addition, keeping the reacting mixture below $20^{\circ} \mathrm{C}$. After complete addition of the amide compound, it was allowed to stand for 30 minutes. The reaction mixture was then concentrated, crystallized and filtered to separate the amine from the reaction mixture. The weight of the compound was taken. The amine was diazotized and coupled with phenol, 1-naphthol and 2-naphthol to give PCN azophenol, PCN azo-1-naphthol and PCN azo-2naphthol respectively, following these procedures;

\section{Diazotization of PCN-aminophenazine}

The diazonium salt solution was prepared by dissolving $\mathrm{PCN}$-aminophenazine $(3.5 \mathrm{~g})$ in distilled water $(90 \mathrm{~mL})$ in a $250 \mathrm{~cm}^{3}$ beaker and concentrated hydrochloric acid $(24 \mathrm{~mL})$ was slowly added. The mixture was stirred until complete dissolution. This solution was cooled in an ice-bath to $0{ }^{\circ} \mathrm{C}$. Sodium nitrite solution (10 $\mathrm{mL}, 10 \%$ ) was added slowly with a dropper to the solution while stirring the mixture to form the diazonium salt. Three phenazine azo compounds were synthesized by coupling the diazonium salt of the amino phenazine, with phenol, 1-naphthol and 2-naphthol respectively.

\section{Synthesis of the PCN azo dyes}

The diazonium salt solution $(125 \mathrm{~mL})$ was prepared in situ and cooled at $0{ }^{\circ} \mathrm{C}$. Phenol/ 1Naphthol/ 2-Naphthol (2.88 g) respectively, was dissolved in $10 \%$ aqueous sodium hydroxide solution $(60 \mathrm{~mL})$ in a $250 \mathrm{~mL}$ beaker. The mixture was stirred until complete dissolution and also cooled to $0{ }^{\circ} \mathrm{C}$ in an ice-bath. The diazonium salt solution $(125 \mathrm{~mL})$ was slowly added to the alkaline solution $(60 \mathrm{~mL})$ while constantly stirring. After complete addition of the diazonium salt solution, the reaction mixture was continually stirred for 5 minutes at $0{ }^{\circ} \mathrm{C}$ to ensure the reaction goes to completion. The reaction mixture was left to stand for 10 minutes. The resulting coloured crystals formed were recovered using suction filtration. It was recrystallized using ethanol and dried in a dessicator. The weight of the resulting compounds were taken using an electronic weighing balance and the melting point were determined.

\section{Acute toxicity test $\left(\mathrm{LD}_{50}\right.$ test) of Pyocyanin and the three azo dyes}

Acute toxicity testing was done on pyocyanin and the azo dyes using Lorke's method [7]. A total of 84 albino mice weighing between 48-160 g were used for this experiment. The mice were brought into the Animal house in the Faculty of Biosciences, Nnamdi Azikiwe University, Awka; and were given a week to acclimatize to the new environment. They were constantly fed and given water. Different doses of each of the test samples, 
based on the body weight of the animals were administered orally to the animals in nine groups, each receiving a dosage of $1000 \mathrm{mg} / \mathrm{kg}, 1500$ $\mathrm{mg} / \mathrm{kg}, 2000 \mathrm{mg} / \mathrm{kg}, 4000 \mathrm{mg} / \mathrm{kg}, 4200 \mathrm{mg} / \mathrm{kg}$, $4400 \mathrm{mg} / \mathrm{kg}, 4600 \mathrm{mg} / \mathrm{kg}, 4800 \mathrm{mg} / \mathrm{kg}$ and 5000 $\mathrm{mg} / \mathrm{kg}$ respectively. The animals were monitored and examined after 24 hours for mortality.

\section{Dyeing potentials of pyocyanin and its azo compounds}

Three dyeing methods were used namely; vat dyeing, direct dyeing and mordant dyeing. The textile materials used were cotton, silk and nylon materials. White fabrics were used throughout the experiment as a control.

\section{Vat dyeing method}

In this method, the dye substance was reduced to leuco dye using sodium dithionite in the presence of sodium hydroxide in a dye bath maintained at $50-60^{\circ} \mathrm{C}$. The fabric materials were immersed in the dye bath and stirred continuously to ensure even dyeing for about 1 hour. It was then spread out and allowed to conform to the original colour of the dye by oxidation by air.

\section{Direct dyeing method}

In this method, the materials were soaked in water for about an hour and then soaked in a hot solution of the dye substance and left overnight. The excess dye was squeezed out of the material and it was then rinsed in cold water and spread to dry, then heat-fixed by ironing for about 10 minutes.

\section{Mordant dyeing method}

In this method, alum was the mordant used. The mordant was dissolved in water and stirred till it dissolved evenly in the dye bath. The materials to be dyed were then soaked in the mordant solution and slowly brought to simmer for about 20-30 minutes and then allowed to cool. When cooled, the materials were then transferred to another dye bath containing the dye solution and then left overnight to ensure the dye was properly fixed onto the fabric. The material was then wrung out and then allowed to dry.

\section{Fastness test of the dyed materials}

The colour fastness test was meant to ensure that the colour of the dyed material is reasonably resistant to colour fading or bleeding due to various types of influences like rubbing, light, perspiration, and washing, etc, which these dyed fabrics are usually exposed to on daily basis. The materials were subjected to the following fastness tests; light fastness test, washing fastness test, rubbing fastness test, acid and alkaline perspiration test. The light fastness grades range from 1-8, while other fastness grades range from $1-5[8]$.

\section{Results and Discussion Extractive yield and physicochemical analysis of the phenazine compounds}

Table 1 shows the results of the physicochemical characteristics of each of the dyes produced.

\section{Acute toxicity test results}

Table 2 shows the results obtained from the acute toxicity tests done on pyocyanin and its azo compounds. The test results showed no mortality for pyocyanin and pyocyanin azo-1-naphthol. One death was recorded for pyocyanin-azophenol $(5000 \mathrm{mg} / \mathrm{kg}$ dosage $)$ while two deaths were recorded for pyocyanin-azo-2-naphthol $(4800 \mathrm{mg} / \mathrm{kg}$ and $5000 \mathrm{mg} / \mathrm{kg}$ dosage respectively). According to the classification of test substances Loomis \& Hayes, 1996 [9], this shows that the test compounds are reasonably non-toxic. 
J. Chem. Soc. Nigeria, Vol. 46, No.2, pp $0393-0399$ [2021]

Table 1: $\quad$ Extractive yield and physicochemical analysis of the phenazine compounds

\begin{tabular}{llllll}
\hline $\begin{array}{l}\text { Phenazine } \\
\text { compound }\end{array}$ & $\begin{array}{l}\text { Weight of dyes } \\
\text { produced }(\mathbf{g})\end{array}$ & $\begin{array}{l}\text { Molecular } \\
\text { weight }(\mathbf{g} / \mathbf{m o l})\end{array}$ & $\begin{array}{l}\text { Melting } \\
\text { point }\end{array}$ & $\begin{array}{l}\text { Percentage } \\
\text { yield }(\%)\end{array}$ & $\begin{array}{l}\text { Colour } \\
\text { observed }\end{array}$ \\
\hline Pyocyanin & 10 & 210 & $133^{\circ} \mathrm{C}$ & & Blue \\
$\begin{array}{l}\text { Pyocyanin } \\
\text { azophenol }\end{array}$ & 3.2 & 316 & $326^{\circ} \mathrm{C}$ & 41 & Dark-green \\
$\begin{array}{l}\text { Pyocyanin azo- } \\
\text { 1-naphthol }\end{array}$ & 4.4 & 366 & $140^{\circ} \mathrm{C}$ & 56.5 & $\begin{array}{l}\text { Purplish- } \\
\text { brown }\end{array}$ \\
$\begin{array}{l}\text { Pyocyanin azo- } \\
\text { 2-naphthol }\end{array}$ & 4.2 & 366 & $105^{\circ} \mathrm{C}$ & 54.5 & red \\
\end{tabular}

Table 2: $\quad$ Acute toxicity test [7] results on pyocyanin and the azo compounds

\begin{tabular}{llllll}
\hline Groups & $\begin{array}{l}\text { Dosage(mg/kg) per } \\
\text { body weight }\end{array}$ & $\begin{array}{l}\text { Pyocyanin } \\
\text { (No. of } \\
\text { deaths) }\end{array}$ & $\begin{array}{l}\text { PCN-PH } \\
\text { (No. of } \\
\text { deaths) }\end{array}$ & $\begin{array}{l}\text { PCN-1N } \\
\text { (No. of } \\
\text { deaths) }\end{array}$ & $\begin{array}{l}\text { PCN-2N } \\
\text { (No. of } \\
\text { deaths) }\end{array}$ \\
\hline 1 & 1000 & - & - & - & - \\
2 & 1500 & - & - & - & - \\
3 & 2000 & - & - & - & - \\
4 & 4000 & - & - & - & - \\
5 & 4200 & - & - & - & - \\
6 & 4400 & - & - & - & - \\
7 & 4600 & - & - & - & - \\
8 & 4800 & - & - & - & 1 \\
9 & 5000 & - & 1 & - & 1 \\
\hline
\end{tabular}

Key - = nil

Table 3: UV-VIS spectroscopy interpretation

\begin{tabular}{ll}
\hline Compound & $\lambda_{\max }(\mathbf{n m})$, Absorbance $(\mathbf{A})$ \\
\hline Pyocyanin & $550(0.964), 750(2.915)$ and $650(2.588)$ \\
Pyocyanin azophenol & $650(0.861)$ and $500(0.74)$ \\
Pyocyanin azo-1-naphthol & $550(2.104)$ and $450(1.175)$ \\
Pyocyanin azo-2-naphthol & $550(1.192), 650(1.37)$ and $750(1.165)$ \\
\hline
\end{tabular}


UV-VIS Spectroscopic analysis of the dyes

Table 3 above, shows the result of the UV-VIS analysis of PCN and the dyes. The results which was run at $200-800 \mathrm{~nm}$ on the electromagnetic spectrum, suggests the different absorbance values of the compounds with respect to their corresponding wavelengths. The spectrophotometric results obtained depict the colours of the compounds which agrees to the results obtained by Al-Rubaie et al., 2011 [10] and Donald et al., 2009 [11].

Dyeing potentials of pyocyanin and the azo dyes Fig. 1 shows the dyeing potentials of pyocyanin using vat, direct and mordant dyeing methods on cotton, silk and nylon.

The results show that the mordant dyeing method was the most efficient as it produced the most intensely coloured fabrics. The vat dyeing method on the other hand, produced the least coloured fabrics. Mordant dyeing method therefore was used for establishing the dyeing potentials of the azo compounds. Fig. 2 shows the dyeing potentials of pyocyanin and the three azo dyes using mordant method. The results show excellent dyeing potentials of the azo dyes on the fabrics (cotton,

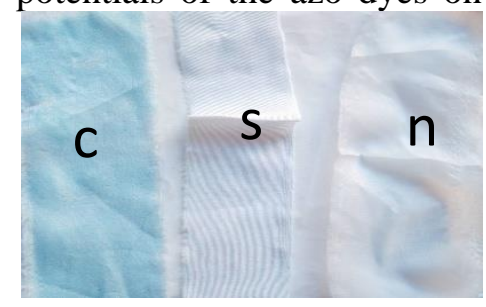

Vat dyeing method

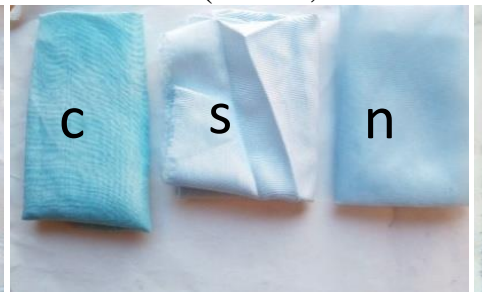

Direct dyeing method silk and nylon) when used as a mordant dye. In each procedure, the colour on the cotton material was more intense compared to the other materials. This could be as a result of the chemical and molecular nature of the fabric.

\section{Results of fastness tests}

The efficacy of the dyes was further tested by carrying out fastness tests on the dyed materials. The fastness tests carried out were; light, washing, rubbing, acid and alkaline fastness tests as shown in figures 3-7.

Table 4 shows the results of the fastness tests of the dyed materials.

The results of the fastness tests (Figures 3 to 7) and Table 4 suggest that the phenazine dyes were reasonably fast on cotton, silk and nylon when mordant dyeing method was used. The dyed cotton fabric showed the best fastness qualities.

Fig 1 Dyeing results of pyocyanin on cotton, silk and nylon using vat, direct and mordant dyeing methods

Key: $\mathrm{c}=$ cotton; $\mathrm{s}=$ silk and $\mathrm{n}=$ nylon
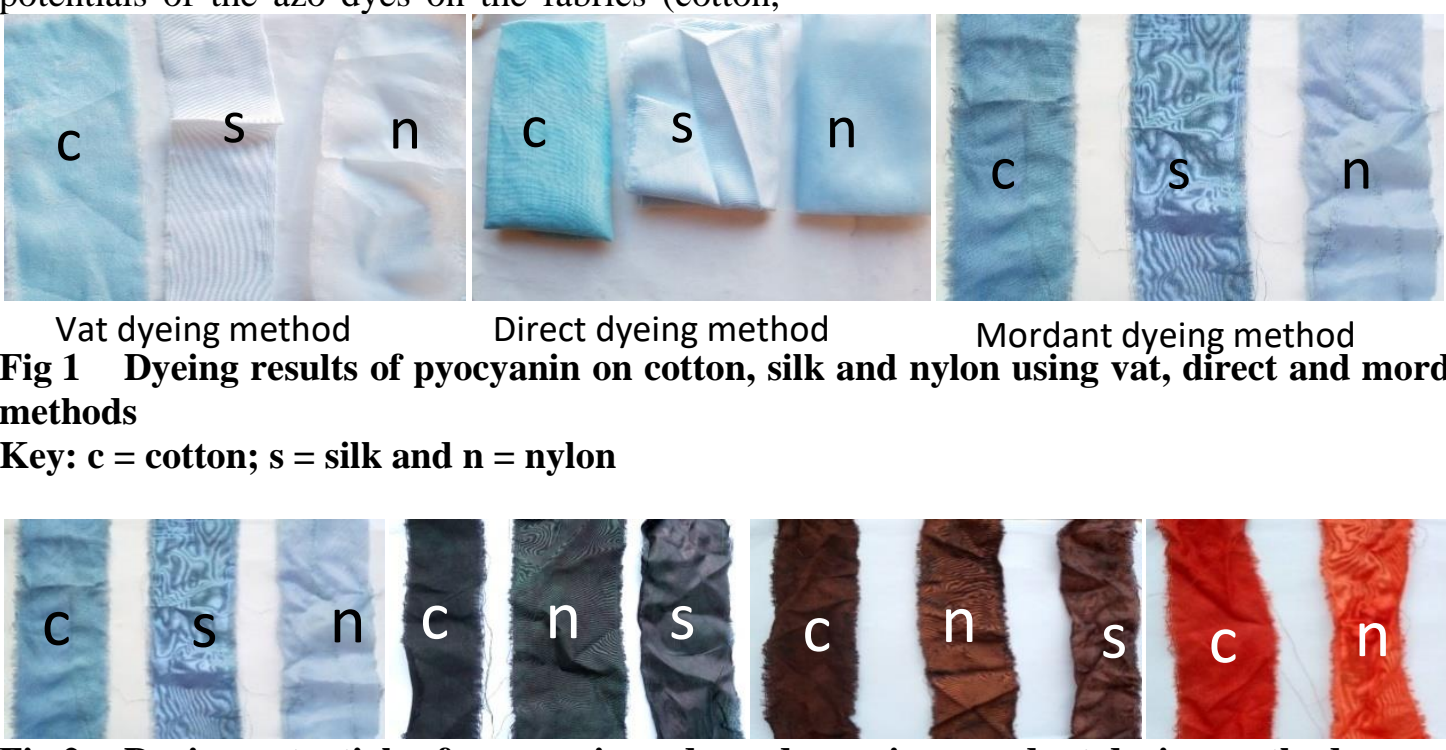

Mordant dyeing method

Fig 2 Dyeing potentials of pyocyanin and azo dyes using mordant dyeing method

Figures 3-7 Results of the fastness tests

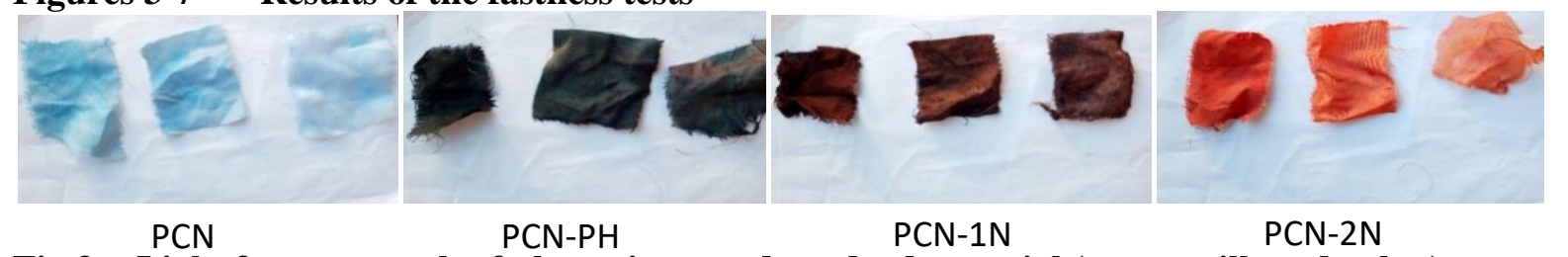

Fig 3 Light fastness result of phenazine mordant-dyed material (cotton, silk and nylon) 


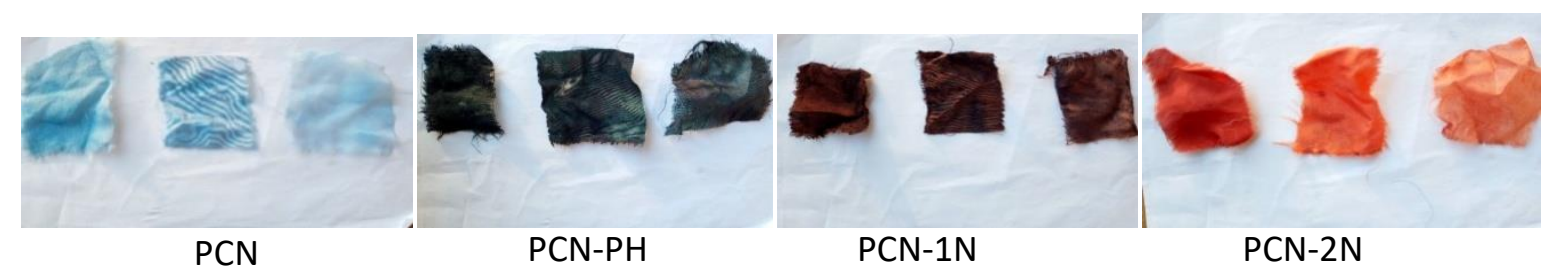

Fig 4 Washing fastness result of phenazine mordant-dyed material (cotton, silk and nylon)

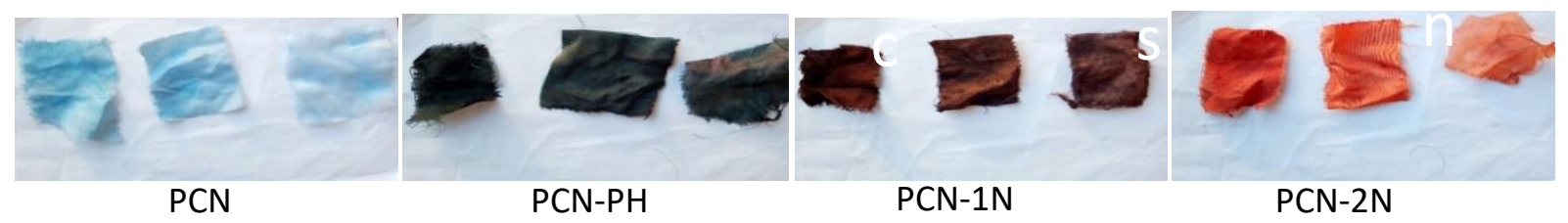

Fig 5 Rubbing fastness result of phenazine mordant-dyed material (cotton, silk and nylon)

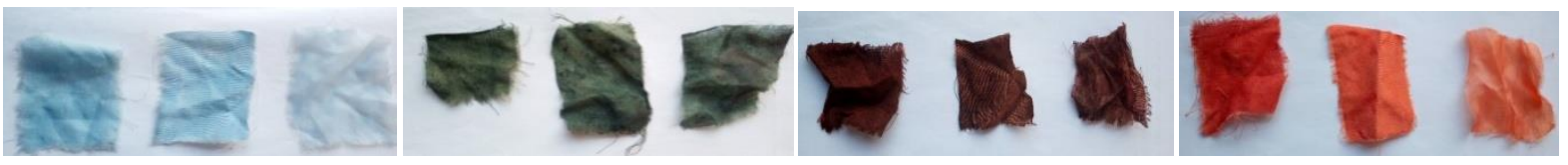

Fig 6 Acid perspiration test result of phenazine mordant-dyed material (cotton, silk and nylon)

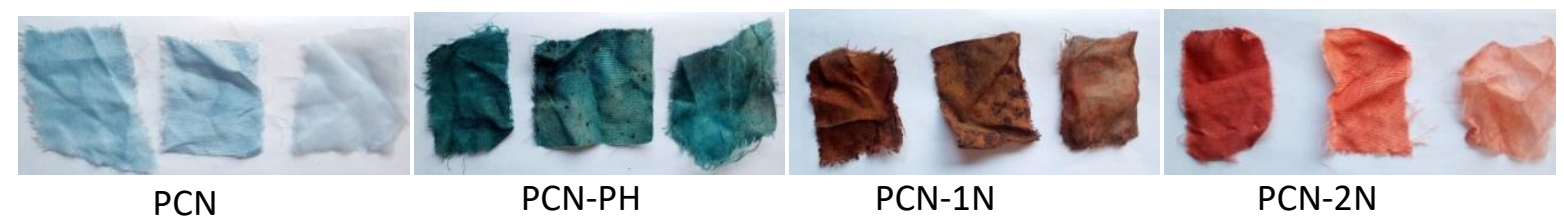

Fig 7 Alkaline perspiration test result of phenazine mordant-dyed material (cotton, silk and nylon)

Table 4: $\quad$ Results of fastness test on the phenazine compounds

\begin{tabular}{|c|c|c|c|c|c|c|}
\hline \multirow{2}{*}{$\begin{array}{l}\text { Phenazine } \\
\text { compound } \\
\text { (color observed) }\end{array}$} & \multirow[t]{2}{*}{ Material } & \multicolumn{5}{|c|}{ Fastness properties } \\
\hline & & Light & Washing & Rubbing & Acid & Alkaline \\
\hline \multirow{3}{*}{$\begin{array}{l}\text { PCN } \\
\text { (Blue) }\end{array}$} & Cotton & 6 & 3 & 4 & 2 & 3 \\
\hline & Silk & 5 & 3 & 4 & 3 & 4 \\
\hline & Nylon & 5 & 2 & 3 & 2 & 2 \\
\hline \multirow{3}{*}{$\begin{array}{l}\text { PCN-PH } \\
\text { (Dark green) }\end{array}$} & Cotton & 7 & 3 & 3 & 4 & 3 \\
\hline & Silk & 6 & 3 & 4 & 3 & 2 \\
\hline & Nylon & 6 & 3 & 3 & 3 & 2 \\
\hline \multirow{3}{*}{$\begin{array}{l}\text { PCN-1N } \\
\text { (Purplish- } \\
\text { brown) }\end{array}$} & Cotton & 7 & 5 & 5 & 4 & 2 \\
\hline & Silk & 6 & 4 & 4 & 4 & 3 \\
\hline & Nylon & 6 & 4 & 4 & 4 & 2 \\
\hline \multirow{3}{*}{$\begin{array}{l}\text { PCN-2N } \\
\text { (Brick red) }\end{array}$} & Cotton & 6 & 4 & 4 & 4 & 3 \\
\hline & Silk & 5 & 4 & 4 & 3 & 2 \\
\hline & Nylon & 6 & 3 & 3 & 2 & 1 \\
\hline
\end{tabular}

Key; Light fastness range from (1-8); Washing, rubbing, acid and alkaline fastness test range from (1-5). 


\section{Conclusions}

Three azo dyes were synthesized from pyocyanin, a phenazine biosynthesized by Pseudomonas aeruginosa, isolated from soil. These three azo dyes are pyocyanin azophenol (dark green), pyocyanin azo-1-naphthol (purplish-brown) and pyocyanin azo-2-naphthol (brick red). UV-Visible spectra of the compounds confirmed the colours obtained. Acute toxicity tests $\left(\mathrm{LD}_{50}\right)$ carried out on the dyes showed them to be reasonably non-toxic. The dyeing potentials of the azo dyes using mordant dyeing, on cotton, silk and nylon textile materials showed them to have good colouration. The dyes also showed reasonable fastness to light, washing, rubbing, acid and alkaline tests. The dyes could be used for textiles and other materials when produced.

\section{References}

1. J.B. Laursen, and J. Nielsen (2004). Phenazine Natural Products: Biosynthesis, Synthetic Analogues and Biological Activity. Chemical Reviews 2004, 104, 1663-1685.

2. J.P. Planet (2018). Principles and Practice of Pediatric Infectious Diseases. (fifth edition).

3. S.H. Alzahrani and F.S. Alqahtani (2016). Pyocyanin Pigment Extracted From Pseudomonas aeruginosa Isolate as Antimicrobial Agent and Textile Colorant. International Journal of Scientific Research.

4. L. Brindley (2009). New Solution for Dye Wastewater Pollution. https://www.chemistryworld.com/news. Retrieved on 23rd Oct. 2019.

5. Y. Mohd, S. Mohd and M. Faqeer (2017). Natural Colourants: historical, Processing and Sustainable Prospects. Nat. Prod. Bioprospect. 7(1): 123-145. Pubmed.

6. P.A.R. El Feghali and T. Nawas (2018). Extraction and Purification Of Pyocyanin: A Simpler and More Reliable Method. MOJ Toxicol

7. D. Lorke (1983). A new approach to practical acute toxicity testing. Arch Toxicol. 54:275-287.

8. B. Oger (1996). Fastness to Light and Washing of Direct Dyes for Cellulosic
Textiles. Studies in Conservation. 41(3): 129-135.

9. T.A. Loomis and A.W. Hayes (1996). Loomis's essentials of toxicology. California Academic press; pp. 208-245.

10. L.R. Al-Rubaie and J.R. MHESSN (2011). Synthesis and characterization of azo dye, para red and new derivatives. E-Journal of Chemistry; 9(1); 465-470.

11. L.P. Donald, M.L. Gany, S.K. George and R.V. James (2009). Introduction to Spectroscopy. Cengage learning, Washington, USA. Ed. $4^{\text {th }}$ : pp. 385-390. 